\title{
Physical and Chemical Characterization of Drag Reducing Polymer Based on Polyvinylpyrrolidone (PVP) in Human Blood Flow
}

\author{
Akram Jassim Jawad $^{\text {a,b,* (D), Auda J. Braihi }}{ }^{\mathrm{a}}$ \\ a: University of Babylon, College of Materials Engineering, Department of Polymer and Petrochemicals \\ Industries, Al Hillah, Iraq \\ b: Queen Mary University of London, School of Engineering and Materials Science, London, UK \\ * Corresponding author: akrammaterials4@gmail.com
}

This article belongs to the regular issue.

(C) 2021, The Authors. This article is published in open access form under the terms and conditions of the Creative Commons Attribution (CC BY) license (http://creativecommons.org/licenses/by/4.o/).

\section{Abstract}

A new attempt to use Polyvinylpyrrolidone (PVP) as a bio-drag reducing polymer agent for human blood flow has been studied. PVP was added at $0,500,750$ and 1000 part per million (ppm) and mixed with human blood at room temperature for 2 minutes. Then, a cone on plate rheometer was used to investigate the effectiveness of PVP agent on blood rheological properties. The results showed significant effecting of PVP on blood fluidity characteristics, where the viscosity decreased as the PVP content increased or as a shear rate increased. For a certain shear rate, the shear stress decreased as PVP content increased. These changes will lead to increased mixing efficiency within the capillaries, increased oxygen transportation, increased tissue perfusion, modified red blood cells (RBCs) distribution, reduced pressure drop gradients, enhanced turbulent flow tendency, enhanced viscoelasticity nature of the blood and its strengthened non-Newtonian pattern. Also, the results showed that the viscosityshear stress relationships become more linear at higher PVP concentrations. PVP addition caused no shifting in UV-absorbing positions and only moderate intensity changing. Atomic force microscopy (AFM) parameters provide other indicators about the role of PVP as a drag reduction agent for blood flow, where all of the amplitude, hybrid and special parameters decreased significantly.

\section{Keywords}

Polyvinylpyrrolidone (PVP)

Blood flow

Biorheology

Drag reducing polymers

(DRPs)

Cone on plate

Atomic force microscopy

Received: 29.03.2021

Revised: 28.04.2021

Accepted: 06.05.2021

Available online: 11.05 .2021

\section{Introduction}

In the last few years, nano-amounts of drag reduction polymeric agents (DRPs) with high solubility, flexibility and molecular weight $\left(M W>10^{6} \mathrm{Da}\right)$ as bio-drag reduction agents in turbulent flow, due to Tom's effect, have been used in different biomedical applications, such as blood flow [1]. DRPs have interesting hemodynamics effects, such as an increase in tissue perfusion, tissue oxygenation, aortic and arterial blood flow, collateral blood flow in rabbits, the number of capillaries in normal and diabetic rats, the concentrations of red blood cells (RBCs) along the vessel wall $[2,3]$. Additionally, DRPs could introduce a decrease in vascular resistance, blood pressure, peripheral vascular resistance, turbulent flow resistance, mechanical damage to blood cells when the blood is in contact with circulatory assist devices, as well as the margination of leukocytes and platelets in the microcirculation. Also, DRPs could modify dynamics of red blood cell (RBC) distribution in microcirculation, preventing them from moving toward the vessel center $[4,5]$.

Different types of polymers were used as DRPs in literature, including high MW polyethylene oxide (PEO) [2, 69], polyacrylamide (PAM) [10-13], and certain polysaccharides [2, 8]. Polyvinylpyrrolidone (PVP) is a vinyl-group polymer, in which the pendant group is the five-membered amide ring. The schematic chemical structure of PVP is shown in Fig. 1. PVP was first patented with good adhesion, good complexation, low toxicity, biocompatibility and good solubility in non-polar and polar solvents. Hence, it has been used in various fields, such as food, cosmetics, pharmaceuticals, adhesives, paints, detergents and energy storages; in last years, PVP was used as drag reduction agent in crude oil flow $[14,15]$. 


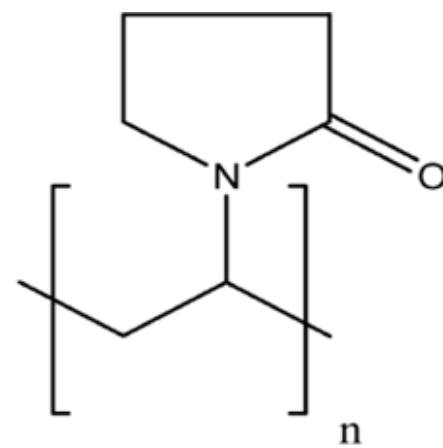

Fig. 1 Schematic chemical structure of PVP [15]

In our present research, we tried to use Polyvinylpyrrolidone (PVP) as a bio drag reducing agent and watersoluble polymer in blood flow at very tiny additive ratios. We added PVP in different concentrations, around o, 500, 750 and $1000 \mathrm{ppm}$. Cone on plate rheometer was applied to check flow characteristics of blood/PVP mixture. Besides that, Fourier-transform infrared (FTIR) spectroscopy, ultraviolet-visible spectroscopy (UV-VIS) and atomic force microscopy (AFM) was utilized to deepen the understanding of physical and chemical interactions between blood ingredients and PVP chains, which have an effect on rheological properties.

\section{Experimental}

Human blood was collected in containers with AcidCitrate-Dextrose (ACD) added as an anticoagulant (10\% by volume) at a local hospital. The DRP used in this study was a Polyvinylpyrrolidone with an average molecular weight of 6o,00o Da with glass transition temperature $\left(T_{\mathrm{g}}\right)$ about $137{ }^{\circ} \mathrm{C}$, supplied by Bio Basic Inc. Company, Canada. PVP was added to human blood at o, 500, 750 and 1000 part per million (ppm). The polymer solution was prepared by dissolving PVP directly in the blood. Then, the solutions were mixed for about $5 \mathrm{~min}$ by using magnetic stirrer at $37{ }^{\circ} \mathrm{C}$, as shown in Fig. 2. Then, the viscosity of blood samples with/without PVP were measured using a Brookfield cone and plate rotational rheometer (DV III-LV) by using the same procedures as in our previous works $[16,17]$, in which the cone model number was 40 , so that the volume of the sample was $2 \mathrm{ml}$ at $37^{\circ} \mathrm{C}$ and $20-60 \mathrm{~s}^{-1}$, temperature and shear rate range, respectively. Also, FTIR spectroscopy (Shimadzu, Japan) was applied by using a drop of the samples between a couple of $\mathrm{NaCl}$ disks. Meanwhile, the samples were characterized by UV-VIS (Shimadzu, Japan) by using quartz double cells method. A drop of samples were dropped on glass substrate for AFM (Angstrom, USA) test by tapping mode procedure with scanning rate equal to $10 \mathrm{~mm} / \mathrm{min}$. AFM images were analyzed by the BY3000 SPM 2.9 program following the ISO 25178-2: 2012 and ASME B46.1 standards.

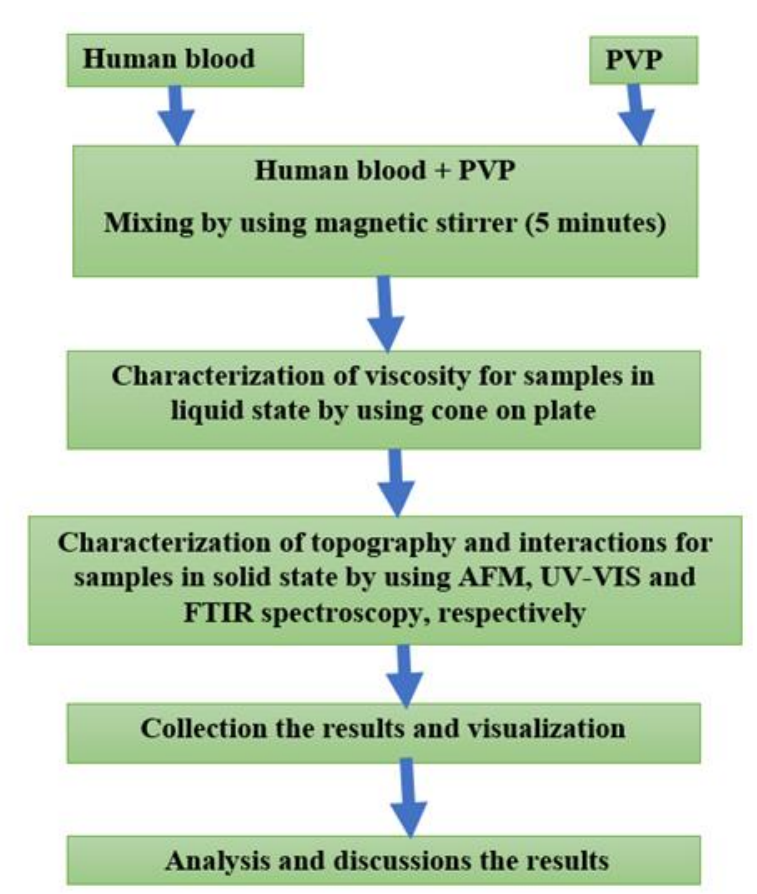

Fig. 2 Flow chart of procedure for experimental work

\section{Results and Discussion}

It is clear from Fig. 3 that, at a certain shear rate, the viscosity decreased as the PVP content increased. This can be attributed to the presence of bulky five membered amide ring within the polymeric chains, where these bulky five membered amide ring could decrease the internal friction between chain-chain, and blood-chain interactions, which leads to lower entanglements that reduce the turbulence flow due to free volume increasing between polymer chains [18]. Therefore, these rings can increase the mixing efficiency within the capillaries, which leads to the increasing of the oxygen transporting due to enhancing the mixing of plasma in the near wall vessel regions. This effect, in turn, resulted in increasing the red blood cells (RBCs) traffic within the vessels. This means that the tissue perfusion will enhance, oxygen delivery, gas exchange will raise, the Fahraeus effect will be reverse and the dynamics RBCs distribution will be modified in the microcirculation within the human body preventing them from accumulation in the vessel centre. The latter manner will improve the pressure levels across vessel regions and decrease the pressure drop gradients. This is due to the redirection of $\mathrm{RBC}$ in this section reducing the vascular resistance as a result of the increment of the wall shear stress, which enhances the endothelium mediated vasodilation [20]. This shear thinning tendency in blood increased as PVP content increased for a fixed shear rate. It can be concluded also that the presence of amide rings in PVP structure will decrease the turbulent flow tendency due to the inverse relationship between the Reynolds number value and the viscosity, where the turbulence increases the apparent viscosity. 


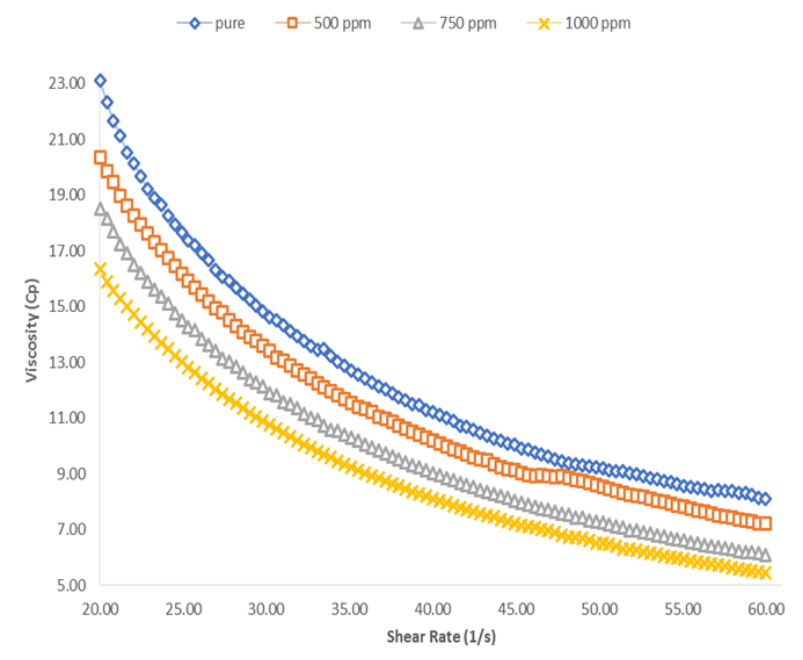

Fig. 3 Viscosity - concentration behaviour of human blood/PVP at different shear rates with different ratios of PVP

The above rheological effects might alter the functional capillary density (FCD), which is the essential factor of survival in haemorrhagic shock. Also, these effects could change the plasma skimming, local haematocrit and Fahraeus-Lindqvist effect. Besides these effects, the presence of polymeric materials in the blood circulation system will enhance the viscoelasticity nature of blood and will strengthen its Non-Newtonian pattern in the velocity profile across the vessel.

Also, Fig. 3 shows that the viscosity decreased as shear rate increased. This result coincides with the Pribush et al. [19] findings, which indicate that high molecular weight polymers decrease the hydrodynamic resistance of blood, thereby improving impaired blood circulation [19]. This explains using PVP as a lubricant agent to reduce friction in contact lenses and eye drops. This proved the previous findings which were related to the increasing the mixing efficiency, especially, in the so called "unstirred boundary plasma layer". This stable layer surrounded RBCs, through which oxygen will transfer by diffusion action. The increment in the mixing state will redistribute the RBCs across the blood vessel, making homogeneity in the velocities of the blood components by shifting the mean velocity of RBCs closer to the corresponding blood mean velocity. These findings agreed with Marhefka et al. [20] results, which indicate that the additives reduce flow separations at micro channel expansions, deflecting $\mathrm{RBC}$ closer to the wall and eliminating the plasma recirculation zone [20]. The overall conclusion of Fig. 3 coincides with the Tom's effect due to the reduction of the turbulent flow resistance in the presence of the polymeric material in blood circulation.

For a certain shear rate, the shear stress decreased as the PVP content increased as in Fig. 4. This finding coincides with the decreasing of viscosity as PVP content increased in the blood stream, which proved the drag reduction of the chosen polymer. At higher shear rates, above $40 \mathrm{~s}^{-1}$, there is a relativity linear relationship with shear

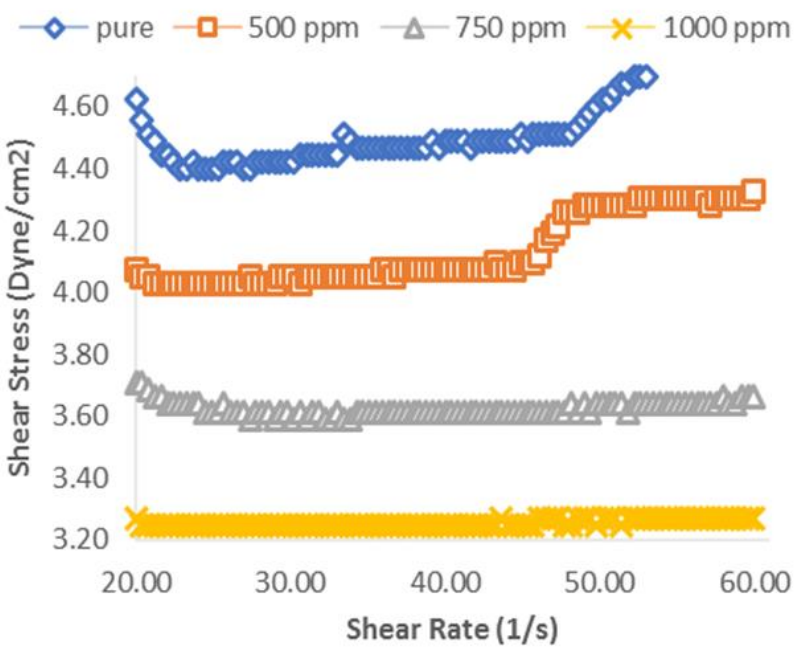

Fig. 4 Shear stress as a function of shear rate of human blood/PVP with different PVP ratios

stresses for low concentrations only, (0-500) ppm; this increment in shear rate decreased at high concentrations (750-1000) ppm. These findings get in agreement with Fig. 5 results, where for certain viscosity, the shear stress decreased as PVP content increased. Also, the shear stressviscosity relationships become more linear at higher concentrations.

Fig. 6 shows the FTIR spectra of blood, PVP and blood containing PVP particle. FTIR spectrum of pure PVP shows an absorption band at $1279 \mathrm{~cm}^{-1}$ which is related to $\mathrm{C}-\mathrm{N}$ bending vibration mode from the pyrrolidone structure, and an absorption band around $1644 \mathrm{~cm}^{-1}$ which belongs to the stretching vibration mode of the $\mathrm{C}=\mathrm{O}$ in the pyrrolidone group. The band at $2885 \mathrm{~cm}^{-1}$ belongs to the $\mathrm{CH}$ stretching mode, the band at $2919 \mathrm{~cm}^{-1}-$ to $\mathrm{CH}_{2}$ symmetric stretching mode, the band at $2983 \mathrm{~cm}^{-1}$ - to asymmetric $\mathrm{CH}_{2}$ stretching mode, and the band around $3464 \mathrm{~cm}^{-1}$ refers to the $\mathrm{OH}$ group. The bands at $1371 \mathrm{~cm}^{-1}$ and $1423 \mathrm{~cm}^{-1}$ correspond to the $\mathrm{CH}$ deformation modes from the $\mathrm{CH}_{2}$ group.

The FTIR spectrum of pure blood shows bands for $\mathrm{COOH},-\mathrm{NH}, \mathrm{C}-\mathrm{H}$ and $\mathrm{C}=\mathrm{O}$ group's blood consists of haemoglobin. It is a tetramer protein, which means it has four

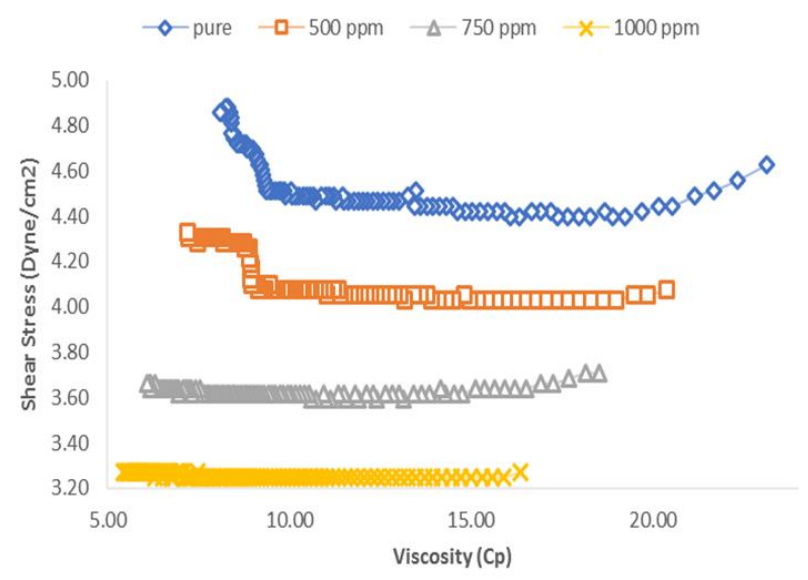

Fig. 5 Shear stress behaviour as a function of Viscosity of human blood/PVP with different PVP ratios 


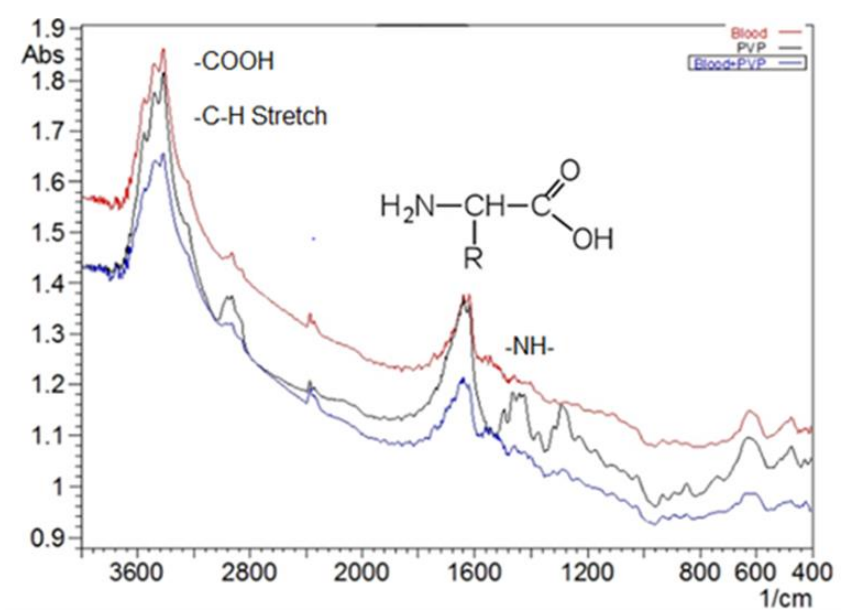

Fig. 6 FTIR absorption spectra of human blood, PVP and blood/PVP mixture

parts. It is made up of 4 polypeptide chains, each polypeptide chain consisting of a linkage of amino acids also known as protein [21]. It is clear from Fig. 6 that there are no new bands appear within the blood/PVP spectrum, which could mean that dissolving PVP polymeric chains within blood have no adverse effects. This is because there are not obvious chemical reactions that introduce new materials and products, which is confirmed by the absence of new bands. This result matching Marhefka et al. [20] assumption that the effect of these DRPs on the drag is associated with their physical interactions with local irregularities of disturbed laminar blood flow [20].

Figs. 7 and 8 represent absorption and transparence UV-VIS spectra of blood, PVP, and blood/PVP, respectively. The PVP addition has a moderate effect on the absorption spectra of UV-VIS by blood, where there is no shifting in the wavenumber, and only the intensity decreases from 3.79 to 3.00. This is due to the little absorbance of PVP for UV-VIS, which is about 1.05 [22]. Therefore, the UV-VIS figures support the FTIR results for biocompatibility of PVP within blood flow due to the blood colour not changing significantly. Consequently, there are no risks from dissolving PVP in blood because it has high biocompatibility that has made it useful in different biomedical applications such as contact lenses and eye drops [15].

The 3D AFM topography images, as in Fig. 9, indicate the role of PVP in reducing the blood viscosity, where the plates seem to be smoother after the PVP addition. This decrease in the roughness of cells surfaces reduces the friction between these cells and makes their flow easier and faster.

Table 1, which was extracted from Fig. 9, explains in detail these PVP effects, with all roughness parameters presented. After PVP addition, all amplitude parameters were affected significantly: the roughness average parameter ( $\mathrm{Sa}$ ) decreased by $58.52 \%$, the root mean square (Sq) decreased by $59 \%$, the peak-to-peak (Sy) decreased by $53.6 \%$ and the ten-point height (Sz) decreased by $80.9 \%$. The hydride parameters decreased also, where the root mean square slop (Sdq) by $86.67 \%$.

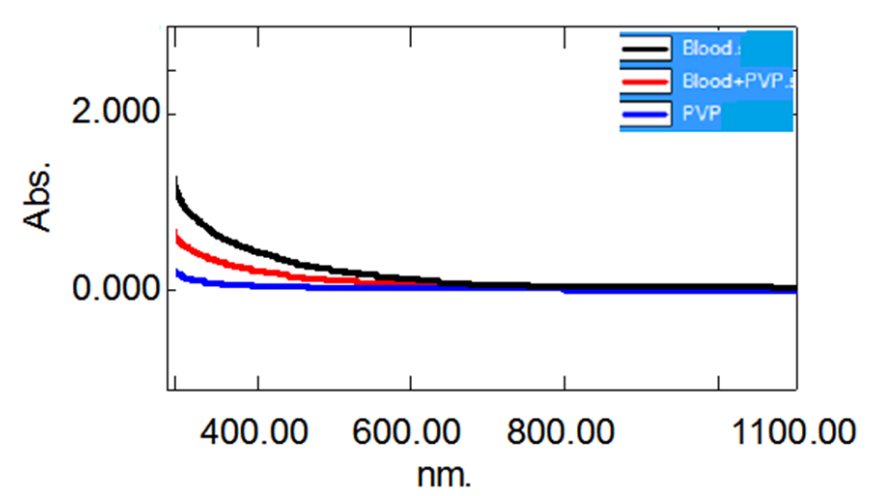

Fig. 7 UV-VIS absorption spectra of human blood, PVP and blood/PVP mixture

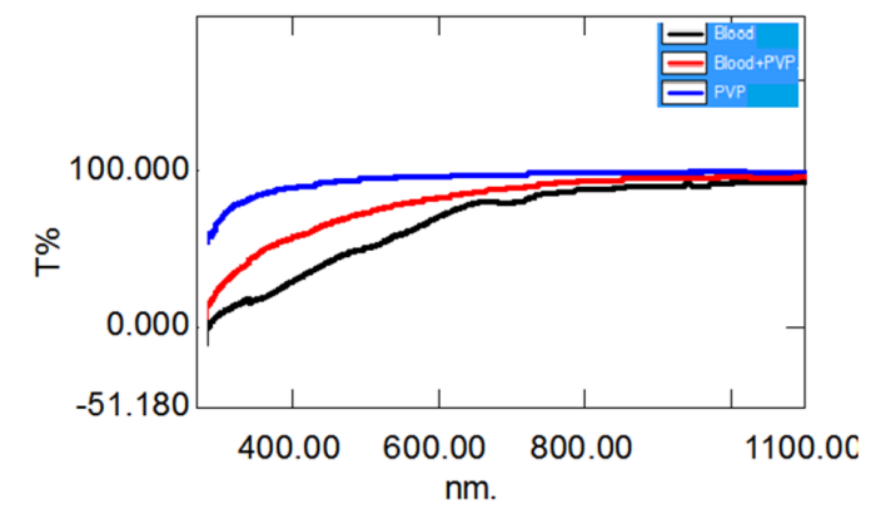

Fig. 8 Transparence UV-VIS spectra of human blood, PVP and blood/PVP mixture

The topography of plates changed after the PVP addition, so that the summits density (Sds) decreased by $99.44 \%$ and the reduced summit height parameter (Spk) decreased by $63.9 \%$. These findings coincide with the reduce in the core roughness depth (Sk) by $50.31 \%$ and reduced valley depth (Svk) by $59.62 \%$, which means the surface possessed less grooves. These surface changes lead in the end to decrease in the core fluid retention index (Sci) by $3.82 \%$ and the surface bearing index (Sbi) by $32.8 \%$.

\section{Conclusions}

PVP could be used as an effective DRP within the flow of human blood, especially in high blood pressure conditions due to its high lubrication ability that introduces pressure drops. The blood viscosity decreased as PVP content increased with nano concentration at a certain shear rate. Also, the blood viscosity decreased as shear rate increased at a certain PVP content with nano concentration. However, there is no change in the blood chemical composition and no shifting in the UV absorbing positions. Consequently, PVP addition makes blood cells smoother, easier and the flow - faster. The possible recommendations could be measuring the haematocrit in each sample, and study the drag reduction in higher shear rates within the veins and compare it with the current range (20-6o s $\left.{ }^{-1}\right)$. Also, studying of the drag reduction in arteries and atherosclerotic arteries and comparing them with the results for veins could be promising. 


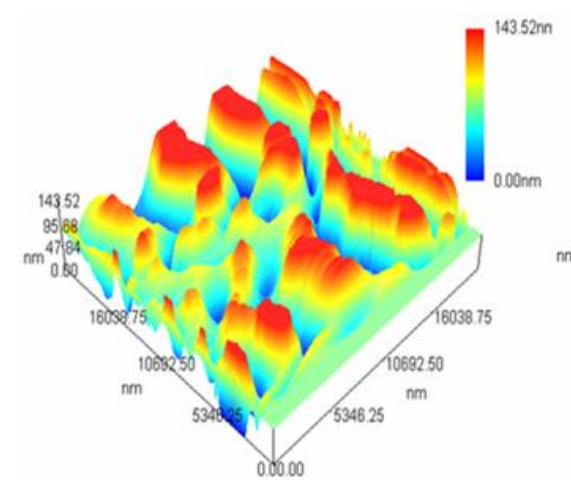

(a)

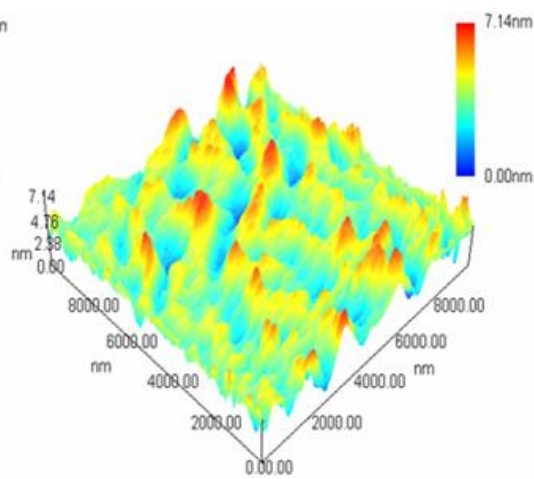

(b)

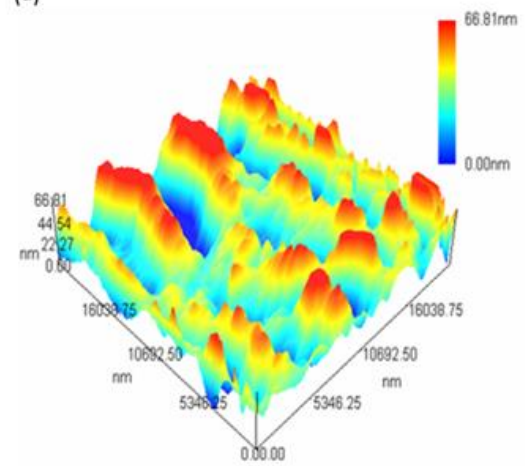

(c)

Fig. 9 Three-dimensional AFM topography images of (a) human blood, (b) PVP and (c) blood/PVP mixture

Table 1 Roughness report for amplitude, hybrid, functional and spatial parameters of human blood, PVP and blood/PVP mixture by using AFM topography analysis

\begin{tabular}{|c|c|c|c|c|c|}
\hline Parameters & & Units & Blood & PVP & Blood+PVP \\
\hline \multirow{6}{*}{$\begin{array}{l}\text { Amplitude } \\
\text { parameters }\end{array}$} & Sa(Roughness Average) & $\mathrm{nm}$ & 34 & 0.844 & 14.1 \\
\hline & Sq(Root Mean Square) & $\mathrm{nm}$ & 42.2 & 1.08 & $17 \cdot 3$ \\
\hline & Ssk(Surface Skewness) & - & -0.0222 & 0.00752 & 0.0233 \\
\hline & Sku(Surface Kurtosis) & - & 2.18 & 3.26 & 2.35 \\
\hline & Sy(Peak-Peak) & $\mathrm{nm}$ & 144 & 7.14 & 66.8 \\
\hline & Sz(Ten Point Height) & $\mathrm{nm}$ & 143 & 4.56 & $27 \cdot 3$ \\
\hline \multirow{2}{*}{$\begin{array}{l}\text { Hybrid } \\
\text { parameters }\end{array}$} & Sdq(Root Mean Square Slope) & $\mathrm{nm}$ & 0.129 & 0.0102 & 0.0462 \\
\hline & Sdr(Surface Area Ratio) & - & 0.788 & 0.00522 & 0.105 \\
\hline \multirow{10}{*}{$\begin{array}{l}\text { Functional } \\
\text { parameters }\end{array}$} & Sbi(Surface Bearing Index) & - & 3.17 & 0.632 & 2.13 \\
\hline & Sci(Core Fluid Retention Index) & - & 1.57 & 1.56 & 1.51 \\
\hline & Svi(Valley Fluid Retention Index) & - & 0.0613 & 0.123 & 0.114 \\
\hline & Spk(Reduced Summit Height) & $\mathrm{nm}$ & 30.2 & 1.17 & 10.9 \\
\hline & Sk(Core Roughness Depth) & $\mathrm{nm}$ & 94.4 & 2.51 & 46.9 \\
\hline & Svk(Reduced Valley Depth) & $\mathrm{nm}$ & 31.7 & 1.19 & 12.8 \\
\hline & Sdc 0-5(0-5\% height intervals of Bearing Curve) & $\mathrm{nm}$ & $13 \cdot 3$ & 1.72 & 8.09 \\
\hline & Sdc $5-10(5-10 \%$ height intervals of Bearing Curve) & $\mathrm{nm}$ & 12.2 & 0.432 & $5 \cdot 35$ \\
\hline & Sdc $10-50(10-50 \%$ height intervals of Bearing Curve) & $\mathrm{nm}$ & 50.5 & 1.37 & 21.8 \\
\hline & Sdc 50-95(50-95\% height intervals of Bearing Curve) & $\mathrm{nm}$ & 67.6 & 1.82 & 31.6 \\
\hline \multirow{2}{*}{$\begin{array}{l}\text { Spatial } \\
\text { parameters }\end{array}$} & Sds(Density of Summits) & $\mathrm{nm}$ & 1.12 & 0.341 & 0.00657 \\
\hline & Fractal Dimension & - & 2.28 & 2.62 & 2.45 \\
\hline
\end{tabular}

\section{Acknowledgements}

We would like to thank the members of the Laboratory of the Department of Polymers and Petrochemical Industries in Babylon University for their great cooperation in accomplishing this work. Also, we would like to thank Dr. Efstathios Kaliviotis, department of mechanical engineering and materials science and engineering at the Cyprus University of Technology, for his great help.

\section{References}

1. Marhefka JN, Kameneva MV. Natural drag-reducing polymers: Discovery, characterization and potential clinical applications. Fluids. 2016;1(2):6. doi:10.3390/fluids1020006

2. Holzner M. Polymers Reduce Drag More than Expected. Physics. 2018;11:29. doi:10.1103/Physics.11.29

3. Gannushkina IV, Grigoryan SS, Kameneva MV, Shakhnazarov AA. The possibility that after circulatory ischemia of the brain the blood circulation can be restored by introducing 
special polymers into the blood. Soviet Physics Doklady. 1981;26:376.

4. Kameneva MV. Microrheological effects of drag-reducing polymers in vitro and in vivo. International Journal of Engineering Science. 2012 Oct 1;59:168-83.

doi:10.1016/j.ijengsci.2012.03.014

5. Kameneva MV, Wu ZJ, Uraysh A, Repko B, Litwak KN, Billiar TR, Fink MP, Simmons RL, Griffith BP, Borovetz HS.

Blood soluble drag-reducing polymers prevent lethality from hemorrhagic shock in acute animal experiments.

Biorheology. 2004;41(1):53-64.

6. Yousif Z. Drag reduction study of xathan gum with polydiallyldimethylammonium chloride (PDDAC) solutions in turbulent flow. Engineering and Technology Journal. 2018;36:891-9. doi:10.30684/etj.336.8A.8

7. Golub AS, Grigoryan SS, Kameneva MV, Malkina NA, Shoshenko KA. Influence of polyethylene oxide on the capillary blood flow in diabetic rats.

Soviet Physics Doklady. 1987;32:620.

8. Polimeni PI, Ottenbreit BT. Hemodynamic effects of a poly (ethylene oxide) drag-reducing polymer, Polyox WSR N-6oK, in the open-chest rat.

J Cardiovasc Pharmacol. 1989;14(3):374-80. doi:10.1097/00005344-198909000-00004

9. Braihi AJ, Rashid FL, Jawad AJ. Investigation of flow behavior characteristics for Iraqi crude oil with different polymeric additives. J Mech Eng Res Dev. 2020;43(4):41-9.

10. Grigoryan SS, Kameneva MV, Shakhnazarov AA. Effect of high molecular weight compounds dissolved in blood on hemodynamics. Soviet Physics Doklady. 1976;21:702.

11. Gannushkina IV, Antelava AL, Baranchikova MV. Suppression of experimental alimentary atherosclerosis with drag reducing polymers. Bulletin of experimental biology and medicine. 1993 Oct;116(4):1219-22. doi:10.1007/BF00802836

12. Mostardi RA, Greene HL, Nokes RF, Thomas LC, Lue T. The effect of drag reducing agents on stenotic flow disturbances in dogs. Biorheology. 1976;13(2):137-41. doi:10.3233/bir-1976-13208
13. Faruqui FI, Otten MD, Polimeni PI. Protection against atherogenesis with the polymer drag-reducing agent Separan AP30. Circulation. 1987;75(3):627-35. doi:10.1161/01.CIR.75.3.627

14. Fischer F, Bauer S. Polyvinylpyrrolidon. Ein tausendsassa in der chemie. Chemie in unserer Zeit. 2009;43(6):376-83. German. doi:10.1002/ciuz.200900492

15. Rashid FL, Braihi AJ, Hashim A, Jawad AJ. Drag Reduction of Iraqi Crude Oil Flow in Pipelines by Polymeric Additives. International Journal of Mechanical Engineering and Technology. 2018;9(13):1049-60.

16. Jawad AJ, Jassim AE, Hadi NJ. Flow behavior of poly (vinyl alcohol)/aluminum oxide nanoparticles solutions as novel method to control the viscosity. Pakistan Journal of Medical \& Health Sciences. 2020;14(4):1550-8.

17. Jawad AJ, Jassim AE, Hadi NJ. Effect of titanium dioxide nanoparticles $\left(\mathrm{TiO}_{2} \mathrm{NPs}\right)$ on rheological characteristics behavior of poly vinyl acetate (PVAc). NanoWorld Journal. 2020;6(3):61-5. doi:10.17756/nwj.2020-080

18. Boyle BM, Heinz O, Miyake GM, Ding Y. Impact of the pendant group on the chain conformation and bulk properties of norbornene imide-based polymers. Macromolecules. 2019 Apr 29;52(9):3426-34. doi:10.1021/acs.macromol.9booo20

19. Pribush A, Hatzkelzon L, Meyerstein D, Meyerstein N. The mechanism of the polymer-induced drag reduction in blood. Colloids and Surfaces B: Biointerfaces. 2013 Mar 1;103:354-9. doi:10.1016/j.colsurfb.2012.11.004

20. Marhefka JN, Zhao R, Wu ZJ, Velankar SS, Antaki JF, Kameneva MV. Drag reducing polymers improve tissue perfusion via modification of the RBC traffic in microvessels. Biorheology. 2009;46(4):281-92. doi:10.3233/BIR-2009-0543

21. Ushasree UV, Jaleeli KA, Ahmad A. Study on infrared spectroscopy of human blood.

Int J Sci Environ Technol. 2006;5:1189-92.

22. Aziz SB, Brza MA, Nofal MM, Abdulwahid RT, Hussen SA, Hussein AM, Karim WO. A comprehensive review on optical properties of polymer electrolytes and composites. Materials. 2020;13(17):3675. doi:10.339o/ma13173675 